\title{
Impact of inpatient rehabilitation on the quality of life of neurological patients in Thailand: A prospective multicenter cohort study
}

Vilai Kuptniratsaikul ( $\nabla$ vilai.kup@mahidol.ac.th )

Mahidol University Faculty of Medicine Siriraj Hospital https://orcid.org/0000-0001-8348-0369

Sivaporn Vongpipatana

Mahidol University Faculty of Medicine Ramathibodi Hospital

Ubonwon Wathanadilokul

Ministry of Public Health

Pranee Lukkanapichonchut

Ministry of Public Health

Kanlaya Ingkasuthi

Ministry of Public Health

Research

Keywords: quality of life, neurological patients, Thailand

Posted Date: July 15th, 2020

DOl: https://doi.org/10.21203/rs.3.rs-41308/v1

License: (9) This work is licensed under a Creative Commons Attribution 4.0 International License.

Read Full License 


\section{Abstract}

Background: Patients with neurological diseases often have residual neurological deficits that can make self-care and ambulation functions difficult, and these obstacles to independence can have an adverse effect on QoL. Many studies have investigated patient QoL in one type of condition. However, data relating to patient $\mathrm{QoL}$ in rehabilitation units that treat a spectrum of disorders are scarce. Accordingly, our aim was to investigate the impact of inpatient rehabilitation on the QoL of neurological patients in Thailand, and to identify factors significantly associated with patient QoL.

Methods: A prospective multicenter cohort study was performed among neurological patients receiving rehabilitation program at 14 tertiary centers during January-December 2012. The Thai Euro QoL five dimensions with three levels (Thai EQ-5D-3L) was used to evaluate the patient's QoL twice, at admission and discharge. It consists of five dimensions: mobility, self-care, usual activities, pain/discomfort, and anxiety/depression with 3 response options for each dimension: no problems, some problems, and extreme problems. Factors related to QoL were analyzed using multiple logistic regression analysis.

Results: Of the 1,197 recruited patients, 567 had spinal cord injury (SCI), 561 had stroke, and 69 had traumatic brain injury (TBI). The mean age was $52.3 \pm 17.5$ years, and $67.4 \%$ were male. Over half $(58.0 \%)$ of patients were admitted for intensive rehabilitation program, and $17.5 \%$ were admitted for investigation. The median QoL score was significantly higher at discharge than at admission, and most subjects (59.6\%) had improved QoL during the rehabilitation period. Multivariate analysis revealed onset to admission interval (OAI) less than 3 months $(p<0.001)$ and intensive rehabilitation program $(p=0.005)$ to be significantly associated with improved QoL. The change in QoL score was greater in the stroke group than in the $\mathrm{SCl}$ and TBI groups. At admission, QoL in the intensive group was below zero compared to the non-intensive group; however, the change in QoL score at discharge was greater in the intensive group.

Conclusions: Inpatient rehabilitation does improve QoL of neurological patients especially participants whose onset of less than 3 months and who are ready for intensive program. Patients with potential for rehabilitation should be admitted during 3 months after onset.

\section{Background}

A favorable quality of life (QoL) is a fundamental desire of all people. The World Health Organization (WHO) defines QoL as an individual's perception of his or her position in life in the context of the culture and value systems in which they live, and in relation to their goals, expectations, standards, and concerns. QoL is a broad ranging concept that is affected in a complex way by a person's physical health, psychological state, personal beliefs, social relationships, and their relationship with the salient features of their environment [1]. Many different definitions have been developed to define QoL. In this study, the focus is on health-related quality of life (HRQoL), which is defined as a person's perception of his or her status relative to their expected physical, emotional, social, and general well-being after experiencing a medical problem or undergoing a medical treatment [2]. 
Patients with neurological diseases often have residual neurological deficits that can make self-care and ambulation functions difficult, and these obstacles to independence can have an adverse effect on QoL. Rehabilitation programs play a valuable role in helping people to recover lost skills, functions, and QoL. Most patients receiving inpatient rehabilitation in Thailand are neurological patients, including those with stroke, spinal cord injury (SCI), or traumatic brain injury (TBI) [3]. After admission in the rehabilitation ward, the aim is to help patients improve their mobility and their ability to perform activities of daily living (ADL). Improvements in mobility and ADL result in improved patient QoL, and this is one of the fundamental goals of rehabilitation. Accordingly, patient QoL is often included as a parameter to evaluate the efficacy of rehabilitation [4].

Previous studies investigated and reported the QoL of patients admitted to the inpatient rehabilitation ward. In stroke patients, Aprile, et al. reported the effects of rehabilitation on QoL using the Short Form-36 Health Survey (SF-36) in 66 chronic stroke patients receiving rehabilitation, and they found improvement in the physical and social function domains after rehabilitation [5]. Manimmanakorn, et al. also reported improved QoL after rehabilitation in 327 stroke patients receiving rehabilitation at 9 centers in Thailand [6]. Gurcay, et al. assessed the QoL of $54 \mathrm{SCl}$ patients using the SF-36 and found patient age, neurological level, functional status, and the presence of complications (especially patients with bladder incontinence) to be factors that influence patient QoL [7]. Weber, et al. studied QoL in TBI patients and reported age and length of hospital stay (LOS) to be predictors of QoL [8].

Many studies have investigated patient QoL in one type of condition, and in rehabilitation units that are dedicated to treating patients with one kind of condition. However, data relating to patient QoL in rehabilitation units that treat a spectrum of disorders are scarce. Accordingly, the aim of this study was to investigate the impact of inpatient rehabilitation on the QoL of neurological patients in Thailand, and to identify factors significantly associated with patient QoL.

\section{Methods}

This prospective multicenter study was a part of a Rehabilitation Services key performance indicator (KPI) project that was performed at 14 tertiary care centers with inpatient rehabilitation services that are located across Thailand [3]. Patients admitted for rehabilitation included patients with SCl, stroke, TBI, or other musculoskeletal diseases. This study recruited only neurological patients receiving inpatient rehabilitation services during January 2012 to December 2012, because neurological patients comprise the largest percentage of patients admitted for rehabilitation in our wards. This study was conducted in accordance with the principles outlined in the Declaration of Helsinki [9]. The protocol for this study was approved by the Institutional Review Board (IRB) of each participating center. Written informed consent was obtained from all study participants.

The types of admission included: (i) intensive rehabilitation (defined as the patient being able to tolerate a rehabilitation program of at least 3 hours per day); (ii) less-intensive rehabilitation (defined as the patient could tolerate a rehabilitation program of one to two hours per day); (iii) investigation(s) (defined 
as a patient who requires any type of examination, such as a regular checkup of the urinary system in $\mathrm{SCl}$ patients); (iv) caregiver training (defined as training for a caregiver who is responsible for providing proper care for a patient); ( $v$ ) treatment of complications (defined as a patient who requires proper care for any serious complications, such as pneumonia, pressure ulcer, or deep vein thrombosis); and, (vi) others (defined as types of admission other than those described above) [3].

Demographic and clinical data were collected, including age, gender, onset to admission interval (OAI), level of care, diagnosis, type of admission, functional score, and length of stay (LOS). The functional score was assessed at admission and discharge using the Barthel Index (BI) (score range: 0-20), with a higher score indicating better function [10]. The Thai Euro QoL five dimensions with three levels (Thai EQ$5 D-3 L)$ was used to evaluate the patient's health-related quality of life (HRQoL) [11, 12]. The EQ-5D-3L consists of the following five dimensions: mobility, self-care, usual activities, pain/discomfort, and anxiety/depression. Each dimension has the following 3 response options: no problems, some problems, and extreme problems. In' spite of the reported limitations of the EQ-5D-3L relative to ceiling effect and lower sensitivity than the SF-12 [13] and SF-36 [14], this tool takes only a few minutes to complete, and it can be used for either face-to-face interview or as a self-assessment that is completed by the patient. EQ5D-3L was assessed at admission and just before discharge. Univariate and multivariate analyses were employed to identify factors significantly associated with improve patient QoL.

\section{Statistical analysis}

Demographic and clinical data were summarized using descriptive statistics. Continuous data are presented as either mean \pm standard deviation or median and range, and categorical data are presented as number and percentage. Wilcoxon signed-rank test and Mann-Whitney $U$ test was used to compare the median QoL within a group and between groups, respectively. Univariate analysis was performed to individually evaluate the significance of each factor. Factors thought to be related to increased patient QoL were analyzed using chi-square test. All factors with a $p$-value of less than 0.20 in univariate analysis were included in multiple logistic regression analysis. A $p$-value less than 0.05 was considered to be statistically significant. All analyses were performed using PASW Statistics version 18.0 (SPSS, Inc., Chicago, IL, USA).

\section{Results}

The mean age of 1,197 recruited patients was $52.3 \pm 17.5$ years, $67.4 \%$ were male, and most subjects (46.4\%) were admitted to university hospitals. SCl was the most common diagnosis (47.4\%), followed by stroke (46.9\%) and TBI (5.8\%). More than half of patients (58.0\%) were admitted for intensive rehabilitation, and $17.5 \%$ were admitted for investigation. The median onset to admission interval (OAI) was 3 months (min: 0.03, max: 492.0 months). The mean Bl at admission (Blad) was $8.8 \pm 5.5$, and the median length of hospital stay (LOS) was 20 days (min: 1, max: 236) (Table 1). The median (min, max) QoL score was significantly greater at discharge than at admission $(p<0.001)$ (Table 2$)$. Moreover, most subjects (59.6\%) had an improved QoL score during the rehabilitation period. Only one-fourth of patients 
had an unchanged QoL score, and 15.5\% had a worse QoL score at discharge than at admission (Table 3).

Table 1

Patient demographic and clinical characteristics

\begin{tabular}{|ll|}
\hline Characteristics & $\mathbf{( N = 1 , 1 9 7 )}$ \\
\hline Age (years), mean \pm SD & $52.3 \pm 17.5$ \\
\hline Male gender, $n$ (\%) & $807(67.4 \%)$ \\
\hline OAl (months), median (min, max) & $3(0.03,492.0)$ \\
\hline Level of care, $n$ (\%) & $556(46.4 \%)$ \\
University hospital & $311(26.0 \%)$ \\
Rehabilitation center & $330(27.6 \%)$ \\
General hospital & \\
\hline Diagnosis, $n$ (\%) & $561(46.9 \%)$ \\
Stroke & $567(47.4 \%)$ \\
SCl & $69(5.8 \%)$ \\
TBI & \\
\hline Type of admission, $n$ (\%) & $694(58.0 \%)$ \\
Intensive rehabilitation & $88(7.4 \%)$ \\
Less-intensive rehabilitation & $210(17.5 \%)$ \\
Investigation(s) & $61(5.1 \%)$ \\
Caregiver training & $24(2.0 \%)$ \\
Treatment of complications & $120(10.0 \%)$ \\
Others & \\
\hline Blad, mean \pm SD & $8.8 \pm 5.5$ \\
\hline LOS (days), median (min, max) & $20(1,236)$ \\
\hline
\end{tabular}


Table 2

Patient median quality of life score compared between admission and discharge

\begin{tabular}{|lccc|}
\hline QoL & Median & $($ min, max $)$ & p-value $^{\#}$ \\
\hline Admission & -0.0260 & $(-0.4540,1.000)$ & $<0.001$ \\
\hline Discharge & 0.3920 & $(-0.4540,1.000)$ & \\
\hline A $p$-value $<0.05$ indicates statistical significance \\
\hline \#Wilcoxon signed-rank test
\end{tabular}

Table 3

The number of patients with change in quality of life score between admission and discharge

\begin{tabular}{|ll|}
\hline Change in QoL score & $\mathbf{n}(\%)$ \\
\hline Increased QoL score & $713(59.6 \%)$ \\
\hline Unchanged QoL score & $298(24.9 \%)$ \\
\hline Decreased QoL score & $186(15.5 \%)$ \\
\hline
\end{tabular}

Table 4 shows the factors that were analyzed for their effect on $\Delta \mathrm{Q} o \mathrm{~L}$ in univariate analysis. Those factors included age, gender, type of admission, diagnosis, Blad, LOS, and OAI. Of those, type of admission, diagnosis, Blad, LOS, and OAI had a $p$-value $<0.2$, so they were included in multivariate analysis. Of those, only admission for intensive rehabilitation (adjusted odds ratio [AOR]: 1.51, 95\% confidence interval [95\% Cl]: $1.13-2.01 ; p=0.005$ ) and OAl of less than 3 months (AOR: $1.92,95 \% \mathrm{Cl}$ : $1.47-2.51 ; p<0.001)$ were found to be significant predictors of increased QoL during rehabilitation period (Table 5). 
Table 4

Univariate analysis for factors significantly associated with increased patient quality of life

\begin{tabular}{|c|c|c|c|c|}
\hline \multirow[t]{2}{*}{ Factors } & \multicolumn{2}{|l|}{$\Delta Q$ oL score } & \multirow{2}{*}{$\begin{array}{l}\text { Crude odds ratio (95\% } \\
\mathrm{Cl})\end{array}$} & \multirow{2}{*}{$\begin{array}{l}p \text { - } \\
\text { value }^{\#}\end{array}$} \\
\hline & $\begin{array}{l}\text { Increased }(n= \\
713)\end{array}$ & $\begin{array}{l}\text { Decreased }(n= \\
484)\end{array}$ & & \\
\hline Age (years), n (\%) & $424(58.6 \%)$ & $300(41.4 \%)$ & 1.00 & 0.382 \\
\hline$<60$ & $289(61.1 \%)$ & $184(38.9 \%)$ & $1.11(0.88-1.41)$ & \\
\hline \multicolumn{5}{|l|}{$\geq 60$} \\
\hline Gender, n (\%) & $226(57.9 \%)$ & $164(42.1 \%)$ & 1.00 & 0.428 \\
\hline Female & $487(60.3 \%)$ & $320(39.7 \%)$ & $1.10(0.86-1.41)$ & \\
\hline \multicolumn{5}{|l|}{ Male } \\
\hline \multirow{2}{*}{$\begin{array}{l}\text { Type of admission, } n \\
(\%) \\
\text { Non-intensive }\end{array}$} & 247 (49.1\%) & $256(50.9 \%)$ & 1.00 & $<0.001$ \\
\hline & $466(67.1 \%)$ & $228(32.9 \%)$ & $2.12(1.67-2.68)$ & \\
\hline \multicolumn{5}{|l|}{ Intensive } \\
\hline Diagnosis, n (\%) & 299 (52.7\%) & $268(47.3 \%)$ & 1.00 & $<0.001$ \\
\hline $\mathrm{SCl}$ & $372(66.3 \%)$ & $189(33.7 \%)$ & $1.76(1.39-2.24)$ & \\
\hline Stroke & $42(60.9 \%)$ & $27(39.1 \%)$ & $1.39(0.84-2.32)$ & \\
\hline \multicolumn{5}{|l|}{ TBI } \\
\hline Blad, n (\%) & $105(51.2 \%)$ & $100(48.8 \%)$ & 1.00 & 0.007 \\
\hline$\geq 15$ & $608(61.3 \%)$ & $384(38.7 \%)$ & $1.51(1.12-2.04)$ & \\
\hline \multicolumn{5}{|l|}{$<15$} \\
\hline LOS, n (\%) & $464(57.1 \%)$ & $349(42.9 \%)$ & 1.00 & 0.011 \\
\hline$<30$ days & $249(64.8 \%)$ & 135 (35.2\%) & $1.39(1.08-1.78)$ & \\
\hline \multicolumn{5}{|l|}{$\geq 30$ days } \\
\hline OAI $(n=1,175), n(\%)$ & $324(50.5 \%)$ & 317 (49.5\%) & 1.00 & $<0.001$ \\
\hline$\geq 3$ months & 376 (70.4\%) & $158(29.6 \%)$ & $2.33(1.83-2.96)$ & \\
\hline \multicolumn{5}{|l|}{$<3$ months } \\
\hline \multicolumn{5}{|c|}{ A $p$-value $<0.05$ indicates statistical significance } \\
\hline${ }^{\#}$ Chi-square test & & & & \\
\hline
\end{tabular}


Table 5

Multivariate analysis for factors that independently predict increased patient quality of life

\begin{tabular}{|c|c|c|c|c|}
\hline Factors & $\begin{array}{l}\text { Crude odds ratio (95\% } \\
\text { Cl) }\end{array}$ & $\begin{array}{l}p- \\
\text { value }^{\#}\end{array}$ & $\begin{array}{l}\text { Adjusted odds ratio (95\% } \\
\text { Cl) }\end{array}$ & $\begin{array}{l}p- \\
\text { value }\end{array}$ \\
\hline \multirow{3}{*}{$\begin{array}{l}\text { Type of } \\
\text { admission } \\
\text { Non-intensive } \\
\text { Intensive }\end{array}$} & 1.00 & \multirow[t]{3}{*}{$<0.001$} & 1.00 & \multirow[t]{3}{*}{0.005} \\
\hline & \multirow[t]{2}{*}{$2.12(1.67-2.68)$} & & \multirow[t]{2}{*}{$1.51(1.13-2.01)$} & \\
\hline & & & & \\
\hline Diagnosis & 1.00 & \multirow[t]{4}{*}{$<0.001$} & 1.00 & \multirow[t]{4}{*}{0.585} \\
\hline $\mathrm{SCl}$ & $1.76(1.39-2.24)$ & & $1.14(0.86-1.51)$ & \\
\hline Stroke & $1.39(0.84-2.32)$ & & $0.95(0.56-1.63)$ & \\
\hline \multicolumn{3}{|l|}{ TBI } & & \\
\hline Blad & 1.00 & \multirow[t]{3}{*}{0.007} & 1.00 & \multirow[t]{3}{*}{0.849} \\
\hline$\geq 15$ & $1.51(1.12-2.04)$ & & $1.03(0.74-1.44)$ & \\
\hline \multicolumn{3}{|l|}{$<15$} & & \\
\hline LOS & 1.00 & \multirow[t]{3}{*}{0.011} & 1.00 & \multirow[t]{3}{*}{0.141} \\
\hline$<30$ days & \multirow[t]{2}{*}{$1.39(1.08-1.78)$} & & \multirow[t]{2}{*}{$1.23(0.93-1.61)$} & \\
\hline$\geq 30$ days & & & & \\
\hline OAI & 1.00 & \multirow[t]{3}{*}{$<0.001$} & 1.00 & \multirow[t]{3}{*}{$<0.001$} \\
\hline$\geq 3$ months & \multirow[t]{2}{*}{$2.33(1.83-2.96)$} & & \multirow[t]{2}{*}{$1.92(1.47-2.51)$} & \\
\hline$<3$ months & & & & \\
\hline \multicolumn{5}{|c|}{ A $p$-value $<0.05$ indicates statistical significance } \\
\hline${ }^{\#}$ Chi-square te & |tiple loqistic reqressic & & & \\
\hline
\end{tabular}

A boxplot of the median QoL score at admission and discharge among patients with stroke, TBI, and $\mathrm{SCl}$ is shown in Fig. 1. The median QoL scores of stroke and TBI patients were below zero at admission; however, the change in the median QoL score between admission and discharge ( $\Delta \mathrm{QoL})$ was much higher in stroke patients than in TBI and SCl patients. A boxplot of the median QoL score at admission and discharge compared between the intensive and non-intensive groups is shown in Fig. 2. The median QoL at admission in the intensive group was below zero, but the change in the median QoL score was significantly greater in the intensive group than in the non-intensive group $(p<0.001)$.

\section{Discussion}


Our study revealed that $60 \%$ of neurological patients receiving inpatient rehabilitation improved their QoL during the rehabilitation period. This finding is consistent with the findings from studies by Manimmanakorn, et al.[6] and Piravej, et al.[15]. Both of those studies performed a multicenter study in stroke patients admitted to 9 centers in Thailand, and both reported significantly improved QoL in stroke patients after rehabilitation. In addition, Ploypetch and Dajpratham performed a single-center study in QoL among disabled patients receiving inpatient rehabilitation in a general rehabilitation ward of a tertiary hospital. They reviewed 200 charts for QoL information using the WHOQOL-BREF-THAI questionnaire, and they found that all domains of QoL had improved at discharge except the social domain [16].

This study also found that $15 \%$ of patients had decreased QoL from admission to discharge. This outcome may due to some of our patients not being ready to undertake a rehabilitation program (nonintensive goal of admission of $42.0 \%$ ), and approximately $30 \%$ had complications during the rehabilitation period. ${ }^{3}$ Moreover, almost $50 \%$ of our subjects were $\mathrm{SCl}$, which is associated with complicated physical disabilities, including motor impairment, difficulty with urination and defecation, and sexual dysfunction, that can adversely impact QoL [17], and some self-evaluated themselves as having poor QoL [18-20].

A prospective observational study was conducted by Coleman, et al. in 32 geriatric patients admitted to an inpatient rehabilitation ward [21]. They studied patient QoL as one of their main outcomes, and they found that QoL evaluated by EQ-VAS significantly improved after 6 weeks of rehabilitation. Their study confirmed the benefits of rehabilitation, even in frail older adults (mean age of 82.9 years). In contrast, Gupta, et al. in 2008 investigated QoL in 30 neurological patients receiving rehabilitation using the WHOQOL-BREF assessment tool, and they found impaired QoL among their study subjects that affected all domains [22]. This finding may be due to the fact that most of the participants in Gupta's study were SCI (18/30), younger age (mean age: $34.6 \pm 11.9)$, and $9(30 \%)$ and $3(10 \%)$ patients had moderate to severe anxiety and depression, respectively. Neither our KPI project nor this study aimed to evaluate the effect of psychological distress on QoL. Further study to investigate the effects of psychological factors on patient QoL are recommended.

Regarding factors that affect QoL during the rehabilitation period, intensive goal of admission and OAl of less than 3 months were both found to be predictors of improved QoL during the rehabilitation period. The fact that intensive rehabilitation was identified may be explained by these patients being ready and eager to participate in a program that will help to improve their ability to function independently, and this would have a resulting positive effect on QoL. Ploypetch and Dajpratham reported improved QoL after rehabilitation in patients admitted for intensive rehabilitation [16]. In 2016, Kuptniratsaikul, et al. conducted a multicenter study in 2,081 rehabilitation inpatients that revealed the most efficient type of admission to be intensive rehabilitation, which could improve functional score better than other types of admission [3]. A 2012 study showed association between better patient QoL perceptions and the level of patient independence [23]. They also found that older adults that considered themselves to be unhealthy had a tendency to report a worse QoL than the QoL reported by healthy older adults. Our intensive 
rehabilitation program aims to improve physical functions and the level of patient independence. Accordingly, it could be anticipated that patients admitted for intensive rehabilitation would realize improvement in their QoL.

Regarding onset to rehabilitation admission interval, we found a duration less than 3 months to be associated with improvement in QoL. This finding is consistent with that reported by Piravej and colleague [15]. They studied QoL among stroke with onset of less than 1 month compared to stroke with onset of more than or equal to 1 month, and they found that an interdisciplinary intensive rehabilitation program could improve QoL in these stroke populations, but that early interdisciplinary intensive rehabilitation was preferred. The 1999 Copenhagen Stroke Study reported that neurological recovery is greatest within 3 months after stroke onset [24]. Taken together, these results suggest that the earlier the rehabilitation is started, the more QoL benefit the patient will gain.

\section{Limitations}

The present study is part of the first prospective multicenter study with a large sample size to report on rehabilitation services in Thailand, however, it has some mentionable limitations. First, there was no longterm follow-up of the patients included in this study. The reported effect on patient QoL reflected the difference in QoL between admission and discharge. It is, therefore, possible that improvements in QoL at the end of rehabilitation may not have been sustained after the patient was discharged. Longer-term follow-up is needed to evaluate the level of sustained effect of rehabilitation after discharge. Second, this study was performed in tertiary hospitals that could provide patients with care delivered by a multidisciplinary team. Since we do not know the effect of other disciplines on changes in patient QoL, our results may not be generalizable to other rehabilitation hospitals with different contexts that could not deliver multidisciplinary care. Third, there are many assessment tools that can be used to evaluate QoL. We chose EQ-5D, which is a non-specific tool, but it is a simple to use tool that we felt would be suitable in our context. Moreover, since the inpatient rehabilitation wards in Thailand are general wards that can treat any kind of condition that requires rehabilitation, we selected EQ-5D since it can be applied in every one of the conditions treated in this study. Fourth, factors related to QoL were analyzed among the entire study cohort. As such, we do not know the effects of the studied factors on each included condition. In addition and as mentioned earlier in this section, the factors affecting QoL that were investigated in this study were mainly physical factors. Further study that includes the effect of psychological and socioeconomic factors on patient QoL should be conducted so that we can gain a more comprehensive understanding of what influences changes in QoL in this patient population.

\section{Conclusion}

A significant increase in the median QoL score from admission to discharge demonstrated that inpatient rehabilitation of neurological patients does improve patient QoL in Thailand. Onset of less than 3 months and admission for intensive rehabilitation were identified as significant predictors of improved QoL. 


\section{Abbreviations}

HRQoL

Health-related quality of life

QoL

Quality of Life

$\mathrm{SCl}$

Spinal Cord Injury

TBI

Traumatic Brain Injury

ADL

Activities of Daily Living

SF-36

36 items Short Form

$\mathrm{KPI}$

Key performance Indicator

IRB

Institutional Review Board

OAI

Onset to Admission Interval

LOS

Length of Stay

$\mathrm{BI}$

Barthel Index

EQ-VAS

EuroQuality of Life-Visual Analogue Scale

WHOQOL-BREF

The World Health Organization Quality of Life (WHOQOL)-BREF questionnaire

\section{Trial Registration}

Registration to TCTR: 20181115001. Registered 14 November 2012 - Retrospectively registered, https://www.clinicaltrials.in.th/TCTR20181115001

\section{Declarations}

\section{Ethical approval and consent to participate}

IRB of Siriraj Hospital COA no.Si608/2011. A written informed consent was obtained from the patients to participate. 


\section{Consent for publication}

Not applicable

\section{Availability of data and materials}

The data that support the findings of this study are not publicly available, but are available from the corresponding author on request.

\section{Competing interests}

The authors declare that they have no competing interests.

\section{Funding}

This study was funded by a grant from the Royal College of Physiatrists of Thailand (grant no.001/2012). The aforementioned funding agency had no influence on the interpretation of data, the final conclusions drawn, or the decision to publish.

\section{Authors' contributions}

VK designed of the work, gave contributions to the conception, performed the analysis, interpret of data, had drafted the work. SV, UW, PL and KI designed the study, conducted the field work and wrote the protocol. All authors contributed to and had approved the submitted manuscript.

\section{Acknowledgements}

The authors gratefully acknowledge the patients that agreed to join this study, and Miss Julaporn Poolium of the Division of Clinical Epidemiology, Department of Research and Development, Faculty of Medicine Siriraj Hospital, Mahidol University for assistance with statistical analysis.

\section{Author Details}

${ }^{1}$ Department of Rehabilitation Medicine, Faculty of Medicine Siriraj Hospital, Mahidol University, Bangkok, Thailand. ${ }^{2}$ Department of Rehabilitation Medicine, Faculty of Medicine Ramathibodi Hospital, Mahidol University, Bangkok, Thailand. ${ }^{3}$ Department of Medical Services, Ministry of Public Health, Sirindhorn National Medical Rehabilitation Centre, Nonthaburi, Thailand. ${ }^{4}$ Department of Rehabilitation Medicine, Ratchaburi Hospital, Ministry of Public Health, Ratchaburi, Thailand. ${ }^{5}$ Rehabilitation Medicine Department, Maharat Nakhon Ratchasima Hospital, Ministry of Public Health, Nakhon Ratchasima, Thailand.

\section{References}


1. Health statistics and information systems. WHOQOL: Measuring Quality of Life. Available at: http://www.who.int/healthinfo/survey/whoqol-qualityoflife/en/ access 30 September, 2018.

2. Cella DF. Measuring quality of life in palliative care. Semin Oncol. 1995;22(2 Suppl 3):73-81.

3. Kuptniratsaikul V, Wattanapa P, Wathanadilokul U, Sukonthamarn K, Lukkanapichonchut P, Ingkasuthi K, et al. The effectiveness and efficiency of inpatient rehabilitation services in Thailand: A prospective multicenter study. Rehabilitation Process Outcome. 2016;5:13-8.

4. Tielemans NS, Schepers VP, Visser-Meily JM, Post MW, van Heugten CM. Associations of proactive coping and self-efficacy with psychosocial outcomes in individuals after stroke. Arch Phys Med Rehabil 2015;96:1484-91.

5. Aprile I, Di Stasio E, Romitelli F, Lancellotti S, Caliandro P, Tonali P, et al. Effects of rehabilitation on quality of life in patients with chronic stroke. Brain Inj. 2008;22:451-6.

6. Manimmanakorn N, Arrayawichanon P, Wattanapun P, Nuntharuksa P, Kuptniratsaikul V. Age-related rehabilitation outcome in stroke patients. J Med Assoc Thai. 2008;91:388-93.

7. Gurcay E, Bal A, Eksioglu E, Cakci A. Quality of life in patients with spinal cord injury. Int J Rehabil Res 2010;33:356-8.

8. Weber KT, Guimarães VA, Pontes Neto OM, Leite JP, Takayanagui OM, Santos-Pontelli TE. Predictors of quality of life after moderate to severe traumatic brain injury. Arq Neuropsiquiatr. 2016;74:409-15.

9. WMA. WMA Declaration of Helsinki: Ethical Principles for Medical Research involving Human Subjects; 2011. Available at: http://www.wma.net/en/30publications/10policies/b3/index.html.

10. Wade DT, Collin C. The Barthel ADL Index: a standard measure of physical disability? Int Disabil Stud. 1988;10:64-7.

11. Sakthong P, Sonsa-Ardjit N, Sukarnjanaset P, Munpan W. Psychometric properties of the EQ-5D-5L in Thai patients with chronic diseases. Qual Life Res 2015;24:3015-22.

12. Tongsiri S, Cairns J. Estimating Population-Based Values for EQ-5D Health States in Thailand. Value Health. 2011;14:1142-5.

13. Brazier J, Jones N, Kind P. Testing the validity of the Euroqol and comparing it with the SF-36 health survey questionnaire. Qual Life Res. 1993;2:169-80.

14. Johnson JA, Coons SJ. Comparison of the EQ-5D and SF-12 in an adult US sample. Qual Life Res. 1998;7:155-66.

15. Piravej K, Konjen N, Cowintaveewat V, Kuptniratsaikul V, Srisa-an Kuptniratsaikul P. Early interdisciplinary intensive rehabilitation significantly improves the quality of life of stroke survivors: a multi-center study. Asian Biomedicine 2014:8:1-9.

16. Ploypetch T, Dajpratham P. Change in quality of life of disabled patients after intensive inpatient rehabilitation at Siriraj Hospital. J Med Assoc Thai. 2011;94:1245-51.

17. de França IS, Coura AS, de França EG, Basílio NN, Souto RQ. Quality of life of adults with spinal cord injury: a study using the WHOQOL-bref. Rev Esc Enferm USP. 2011;45:1364-71. 
18. Lee JS, Kim SW, Jee SH, Kim JC, Choi JB, Cho SY, et al. Factors affecting quality of life among spinal cord injury patients in Korea. Int Neurourol J. 2016;20:316-20.

19. Ebrahimzadeh MH, Soltani-Moghaddas SH, Birjandinejad A, Omidi-Kashani F, Bozorgnia S. Quality of life among veterans with chronic spinal cord injury and related variables. Arch Trauma Res. 2014;3:e17917.

20. Simpson LA, Eng JJ, Hsieh JT, Wolfe DL, Spinal Cord Injury Rehabilitation Evidence Scire Research Team. The health and life priorities of individuals with spinal cord injury: a systematic review. J Neurotrauma. 2012;29:1548-55.

21. Coleman SA, Cunningham CJ, Walsh JB, Coakley D, Harbison J, Casey M, et al. Outcomes among older people in a post-acute inpatient rehabilitation unit. Disabil Rehabil. 2012;34:1333-8.

22. Gupta A, Deepika S, Taly AB, Srivastava A, Surender V, Thyloth M. Quality of life and psychological problems in patients undergoing neurological rehabilitation. Ann Indian Acad Neurol. 2008;11:22530.

23. Trentini C, Wagner G, Chachamovich E, Figueiredo M, da Silva L, Hirakata V, et al. Subjective perception of health in elderly inpatients. Int J Psychol. 2012;47:279-86.

24. Jørgensen HS, Nakayama H, Raaschou HO, Olsen TS. Stroke. Neurologic and functional recovery the Copenhagen Stroke Study. Phys Med Rehabil Clin N Am. 1999;10:887-906.

\section{Figures}

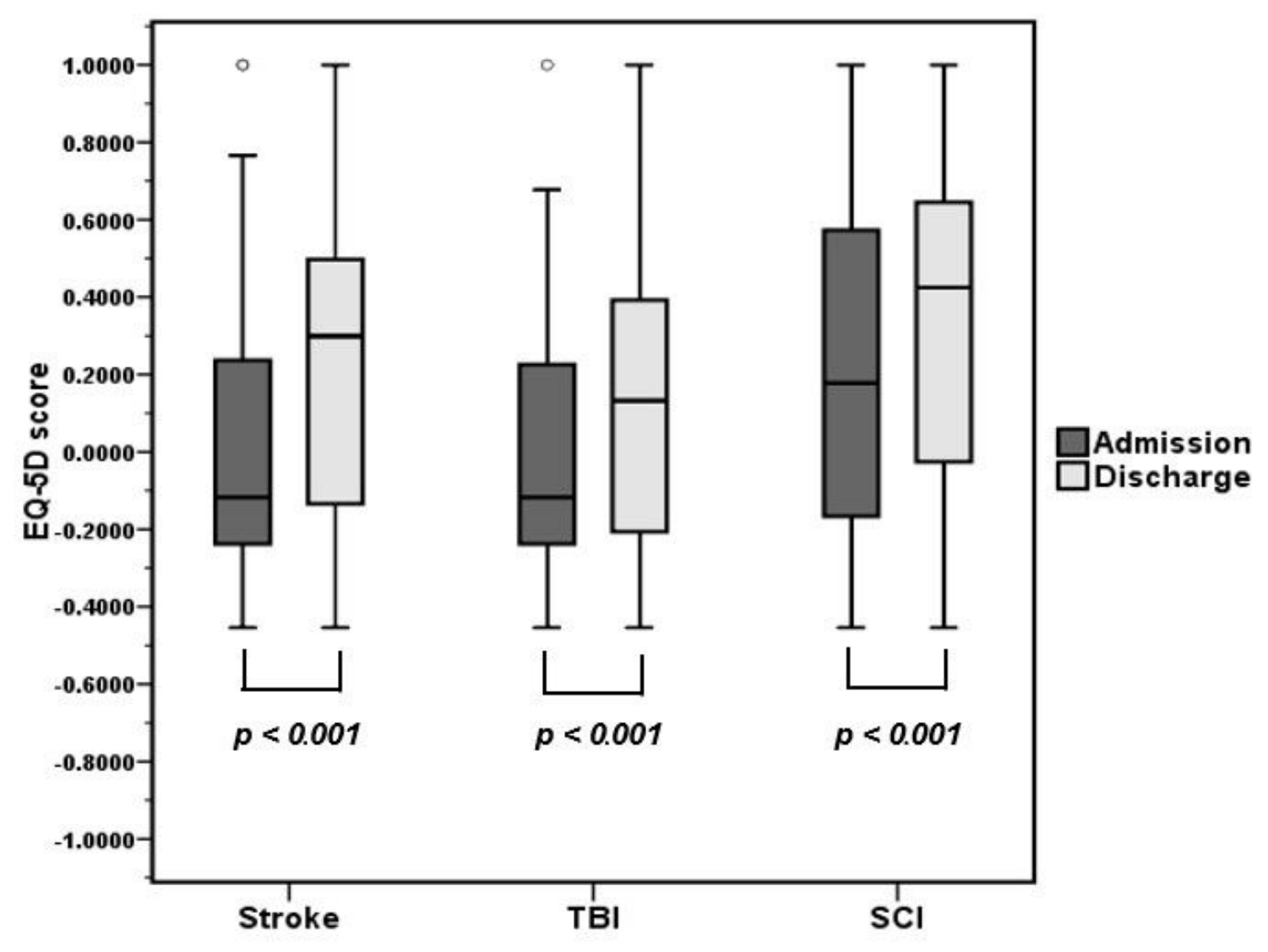


Figure 1

Boxplot of median QoL compared between admission and discharge among stroke, TBI and SCI

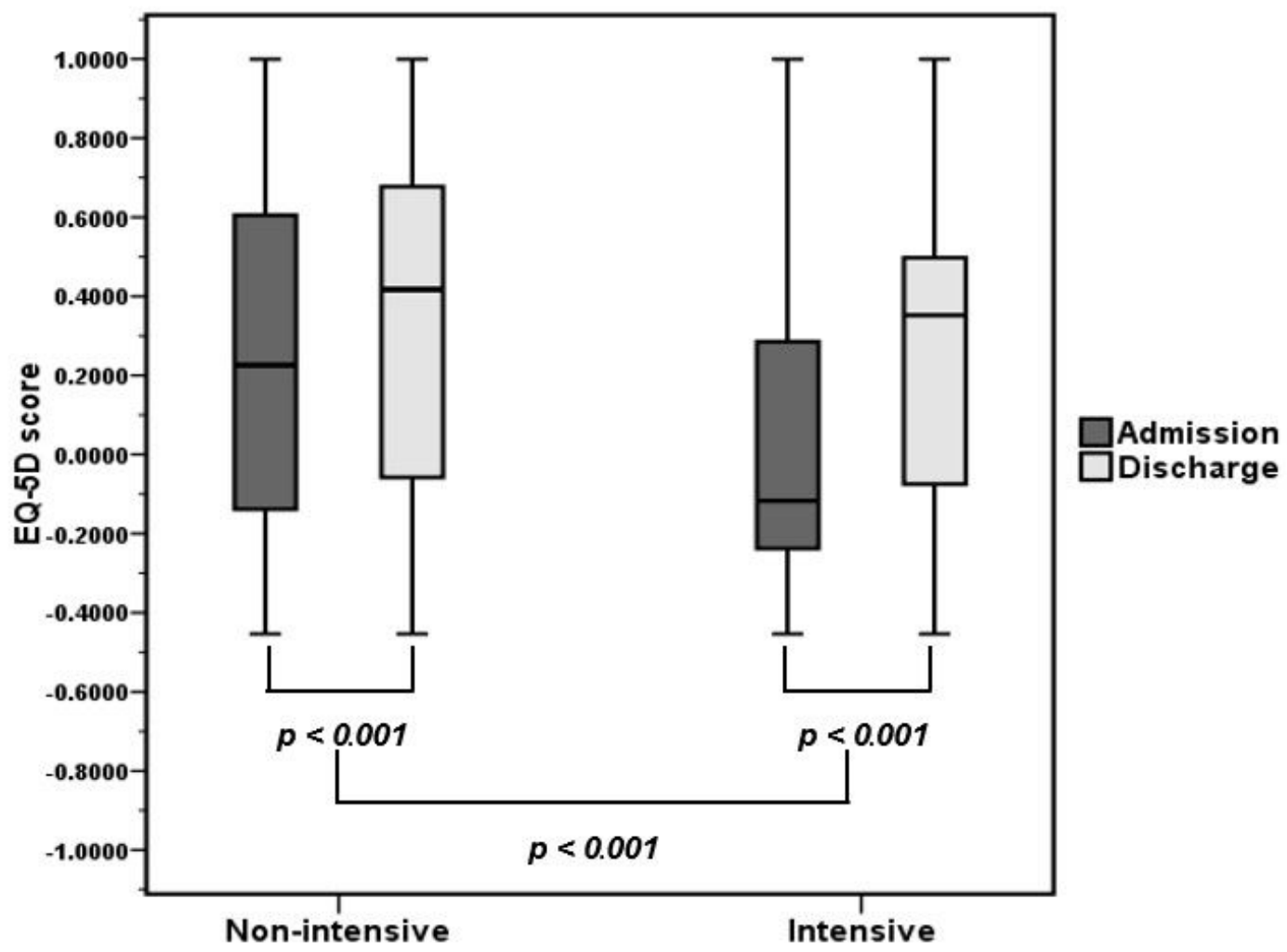

Figure 2

Boxplot of median QoL compared between admission and discharge among patients with intensive and non-intensive types of rehabilitation admission 